Original Research Article

\title{
Knowledge, attitude and practice of pharmacovigilance among community pharmacists in Delhi, India
}

\author{
Ravinder K. Sah ${ }^{1 *}$, Rakhamaji D. Chandane ${ }^{1}$, Krishna ${ }^{1}$, Sachin Manocha ${ }^{2}$, Ajita Kapur ${ }^{1}$
}

${ }^{1}$ Department of Pharmacology, Lady Hardinge Medical College, New Delhi 110001, India ${ }^{2}$ Department of Pharmacology, School of Medical Sciences and Research, Sharda University, Greater Noida, Uttar Pradesh 201306, India

Received: 13 January 2017

Revised: 17 January 2017

Accepted: 13 February 2017

*Correspondence to:

Dr. Ravinder K. Sah,

Email: ravindersah@gmail.com

Copyright: (C) the author(s), publisher and licensee Medip Academy. This is an openaccess article distributed under the terms of the Creative Commons Attribution NonCommercial License, which permits unrestricted noncommercial use, distribution, and reproduction in any medium, provided the original work is properly cited.

\begin{abstract}
Background: Lack of knowledge of Pharmacovigilance (PhV) and Adverse Drug Reactions (ADRs) reporting culture among the prescribers have been identified as major factors for under reporting of ADRs. In an attempt to increase the reporting many countries have allowed pharmacists to report ADRs. This study was planned to assess the knowledge, attitude and practices of $\mathrm{PhV}$ among community pharmacist in Delhi, India.

Methods: Cross sectional, questionnaire based study was conducted to evaluate the knowledge, attitude and practice of $\mathrm{PhV}$ among 200 community pharmacists of Delhi (west Delhi) India.

Results: Majority (74\%) of the respondents felt that ADR reporting is necessary but only 9\% were aware of existing PhV Program of India. Only 5\% of pharmacists knew about elements of $\mathrm{PhV}$. Forty percent (40\%) of pharmacists did not know where to report ADRs and $26 \%$ felt that there is no need to report ADRs. Significant number (77\%) of pharmacists felt that ADRs reporting will damage their image. $96 \%$ never try to find ADRs and in case if they get ADRs from patients, majority (95\%) of them never report to anybody. Almost all $(96 \%)$ of respondents cited busy schedule as the main reason for non-reporting and $86 \%$ said that it will be very convenient if ADRs are collected by someone from them.

Conclusions: Community pharmacists had positive attitude towards ADRs reporting but their knowledge and practice regarding $\mathrm{PhV}$ need to be improved. There is a need of regular training to increase their role in $\mathrm{PhV}$.
\end{abstract}

Keywords: ADR reporting, Community Pharmacist, Pharmacovigilance

\section{INTRODUCTION}

Adverse drug reactions (ADRs) are one of the major causes of mortality, morbidity, unexpected hospitalization and increased cost of healthcare globally. ${ }^{1-}$

4 Amongst the total ADRs, $0.2 \%$ to $41.3 \%$ lead to emergency hospitalizations worldwide and $28.9 \%$ of these ADRs are avertable. ${ }^{5}$ Several studies have reported that misuse and irrational prescribing of drugs account for majority of ADRs. ${ }^{1-4}$ India is one of the largest drug consuming countries in the world with substantial irrational prescribing and therefore increased likelihood of development of ADRs. ${ }^{6}$ Thus, early identification and reporting of ADRs is extremely important from health and economical point of view.

In India, activities related to the detection, monitoring and reporting of adverse events (AE) are growing since 1986. ${ }^{7}$ Ministry of Health and Family Welfare, Government of India rechristened these activities as the Pharmacovigilance Program of India (PvPI) which became operational since July $2010 .^{8}$

Under PvPI, the spontaneous reporting of ADRs is considered as the main mode of reporting. Early detection of signals for new, rare and serious ADRs is possible through spontaneous reporting of ADRs. It is also one of 
the cheapest methods used worldwide for monitoring the safety of medicines. By spontaneous reporting system prescribers have contributed to the detection, monitoring, and reporting of $\mathrm{AE}$ experiences by the patients. ${ }^{9,10}$

Pharmacovigilance $(\mathrm{PhV})$ programme plays a vital role in ensuring the patient's safety however; under-reporting is a one of the major problem in the success of PvPI. Till date over one lac Individual Case Safety Reports (ICSRs) have been submitted in WHO-vigibase from India but ADRs reporting rate is only $1 \%$ from India as compared to $5 \%$ from rest of the world. ${ }^{11,12}$

In an attempt to increase reporting, many countries have allowed hospital pharmacists, community pharmacists, nurses and even patients to report ADRs. ${ }^{13}$

Community pharmacists have an opportunity to detect possible ADRs as they are dealing with the counter prescriptions and hence they can help in management and reporting of the ADRs. ${ }^{14,15}$ As per national data of 2014, total number of allopathic doctors is $9,38,861$ and total number of registered pharmacists is $6,64,176 .{ }^{16}$

Therefore pharmacists can significantly contribute in PvPI by reporting ADRs. In a recent study, Kalaiselvan V et al. observed that majority of ADRs were reported by physicians (64.4\%); followed by nurses $(20.4 \%)$ and pharmacists $(15.1 \%)$ in India. ${ }^{11}$ So, why despite of huge number of pharmacists in India their participation in PvPI is very minimal? To find answer of this question we planned this study to evaluate knowledge, attitude and practice of $\mathrm{PhV}$ among community pharmacists.

\section{METHODS}

A cross-sectional questionnaire-based study was conducted on 200 community pharmacists of Delhi (west Delhi), India from June 2016 to September 2016. Structured pretested questionnaire based on the PvPI containing total 18 items to evaluate knowledge, perception and practices; was used. Participants were explained the purpose of study and were requested to complete and return the questionnaire form. Results were expressed in percentages.

\section{RESULTS}

All the 200 community pharmacists were registered with pharmacy council of India and providing their services in west Delhi, India.

Majority of them i.e. $92 \%$ and $91 \%$ respectively were not aware of elements of $\mathrm{PhV}$ and national programme related to ADRs reporting. In this study, 26\% of community pharmacists opined that there is no need to report ADRs. Results have shown that $46 \%$ of respondents did not know about what to report and $40 \%$ of respondents did not know where to report ADRs (Table 1).
Amongst the total community pharmacists evaluated, $74 \%$ felt that ADRs reporting should be necessary (Table 2 ); though $95 \%$ of community pharmacists never reported any ADRs to anybody (Table 3).

In fact $96 \%$ of the respondents agreed that they have never tried to find ADRs. In case the pharmacists got ADRs through patients either they $(70 \%)$ used to ask the patients to consult the prescribers or they $(14 \%)$ used to change the brand of the drug without consulting prescribers (Table 3).

In our study $77 \%$ of respondents felt that ADRs reporting will spoil their image in general population. Busy schedule was cited by $96 \%$ of community pharmacists as a reason for not reporting ADRs and $86 \%$ felt that ADRs forms should be collected by someone from their pharmacy stores (Figure 1) (Table 2).

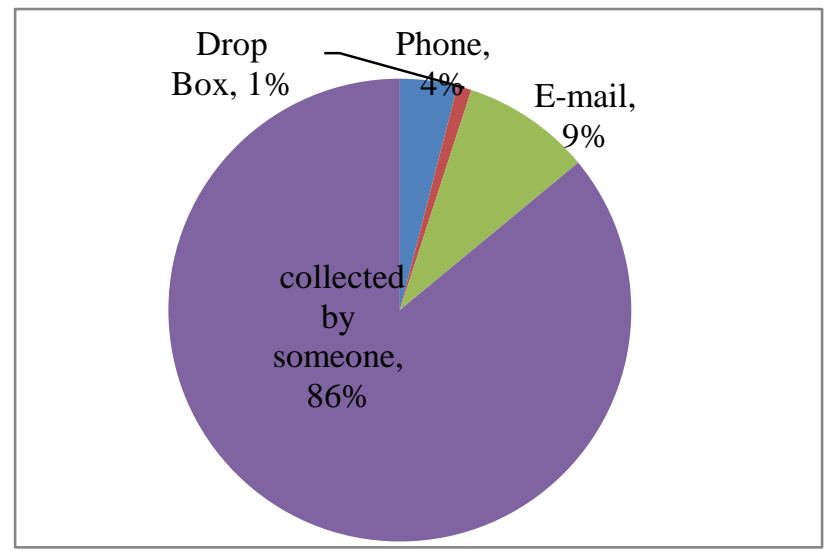

Figure 1: Preferred mode by community pharmacists to report ADRs.

\section{DISCUSSION}

Shift of pharmaceutical activities from west to east and availability of around 80,000 brands of drugs in the Indian market has lead to rapid growth of $\mathrm{PhV} .{ }^{17,18}$

Hence, it is imperative to develop task force to monitor and report ADRs to ensure patient safety. A number of studies suggest that as pharmacists have a vast knowledge on drugs and therapeutics hence they can play a pivotal role in the identification, detection, prevention and management of ADRs. ${ }^{11,19-21}$

In our study only $17 \%$ respondents correctly defined ADR contrary to $69.7 \%$ of pharmacists in a study by Suyagh $\mathrm{M}$ et al. ${ }^{22}$

Regarding knowledge about reporting of ADRs, Nagaraju $\mathrm{K}$ et al. observed that $69 \%$ of pharmacists were not aware about the same; which was parallel with finding (66\%) of our study. ${ }^{23}$ Meta-analysis by Bhagavathula AS identified that the majority $(81 \%)$ of pharmacists were unaware of PvPI in India. ${ }^{18}$ 
Table 1: Knowledge of pharmacist (N=200) towards Pharmacovigilance (PhV) and Adverse Drug Reaction (ADR) monitoring and reporting.

\begin{tabular}{|c|c|c|}
\hline S. No. & Questions & Results $(\%)$ \\
\hline 1. & Correct definition of Adverse drug reaction (ADR) is: & \\
\hline a. & $\begin{array}{l}\text { A response to a drug which is noxious and unintended, and which occurs at doses normally used for } \\
\text { the prophylaxis, diagnosis, or therapy, or for the modification of physiological function. }\end{array}$ & 17 \\
\hline b. & $\begin{array}{l}\text { Untoward medical occurrence(s) that may present during treatment with a pharmaceutical product } \\
\text { and which does not necessarily have a causal relationship with treatment. }\end{array}$ & 9 \\
\hline c. & $\begin{array}{l}\text { Unwanted and unavoidable pharmacodynamic effects which can be predictable and occur at } \\
\text { therapeutic doses. }\end{array}$ & 26 \\
\hline d. & Harmful effect(s) of drug at any dose when taken for treatment purpose & 48 \\
\hline 2. & Reporting of ADR is: & \\
\hline a. & Mandatory & 9 \\
\hline b. & Voluntary & 25 \\
\hline c. & No need to report & 26 \\
\hline d. & Not know & 40 \\
\hline 3. & What to report: & \\
\hline a. & serious adverse event (SAE) & 19 \\
\hline b. & Adverse Event & 3 \\
\hline c. & Adverse drug reaction (ADR) & 20 \\
\hline d. & Side Effect & 7 \\
\hline e. & All & 5 \\
\hline f. & Not know & 46 \\
\hline 4. & Whom to report ADRs: & \\
\hline a. & Indian Pharmacopeia Commission & 3 \\
\hline b. & ADR monitoring centre of institution/hospital & 6 \\
\hline c. & Treating physician & 8 \\
\hline d. & Pharmaceutical company & 20 \\
\hline e. & Any of the above & 0 \\
\hline f. & No need to report & 24 \\
\hline g. & Do not know & 40 \\
\hline 5. & ADR reporting to be done for: & \\
\hline a. & Allopathic medicines & 25 \\
\hline b. & Indian system of Medicine & 2 \\
\hline c. & Medical devices & 0 \\
\hline d. & All & 7 \\
\hline e. & Not know & 40 \\
\hline f. & No need to report & 26 \\
\hline $\begin{array}{l}6 . \\
\text { a. }\end{array}$ & $\begin{array}{l}\text { Do you know the name of national programme related to ADR reporting? If yes please name it: } \\
\text { Yes (correct name) }\end{array}$ & 9 \\
\hline b. & No & 91 \\
\hline 7. & What are the elements of PhV? & \\
\hline a. & Detection, Assessment, Understanding, Prevention & 5 \\
\hline b. & Diagnosis, Treatment, Monitoring & 2 \\
\hline c. & Identification, Standardization, Prescription & 1 \\
\hline d. & Do not know & 92 \\
\hline
\end{tabular}

Further like other authors as a reason of under-reporting, we found that $24 \%$ of pharmacists were in impression that ADRs reporting is not needed and $40 \%$ of pharmacists did not know where to report ADRs. ${ }^{23,24}$ This finding is also consistent with the study from Saudi Arabia where lack of knowledge about $\mathrm{PhV}$ programme, where to report and how to report ADRs were revealed as major barriers in reporting of ADRs. ${ }^{25}$ Result pertaining to knowledge of community pharmacists regarding ADRs monitoring and reporting system was in agreement with other national and international studies which found that majority of pharmacists were not aware of $\mathrm{PhV}$ programme and its elements. ${ }^{16,22,23,26}$

In this study, $74 \%$ of community pharmacists felt that reporting of ADRs should be necessary. Similarly Suyagh M. et al. and Prakasam A et al. found that majority of community pharmacists believe that reporting of ADRs should be necessary. ${ }^{22,24}$ In consistence with our finding, Salim et al. reported that $55 \%$ of community pharmacists opined that by reporting ADRs patients will get benefits. $^{13}$ 
Table 2: Attitude of pharmacists ( $\mathrm{N}=\mathbf{2 0 0})$ towards ADRs monitoring and reporting.

\begin{tabular}{|llc|}
\hline S. No. & Questions & Results (\%) \\
\hline 1. & ADR reporting should be necessary? & 74 \\
a. & Yes & 26 \\
\hline b. & No & \\
\hline 2. & Who get benefits from ADR Reporting? & 10 \\
a. & Doctors & 0 \\
b. & Nurses & 5 \\
c. & Pharmacist & 66 \\
d. & Patients & 8 \\
e. & Pharmaceutical company & 5 \\
f. & Health regulatory authorities & 6 \\
g. & All & \\
\hline 3. & Does ADR reporting spoil your image as a pharmacist? & 77 \\
a. & Yes & 23 \\
b. & No & \\
\hline & Do you need information on drug causing ADRs? & 21 \\
4. & Yes (why) & 15 \\
a. & I. For future reference & 6 \\
& II. To inform patients & 79 \\
b. & No (why) & 60 \\
\hline & I. Doctors will take care & 19 \\
\hline 5. & II. I have information on drug causing ADRs & 67 \\
a. & Voluntary reporting & 10 \\
b. & Mandatory reporting & 23 \\
c. & Need base reporting & \\
\hline 6. & Preferred mode to report ADRs - & 4 \\
a. & Phone & 1 \\
b. & Drop Box & 96 \\
c. & E-Mail & 46 \\
d. & Should be collected by someone & \\
\hline 7. & Reason for not reporting: & \\
a. & Busy Schedule & \\
b. & Not very helpful for business & \\
\hline & $\quad$ & \\
\hline
\end{tabular}

On asking for the need of information on drugs causing ADRs, $79 \%$ of community pharmacists denied because majority $(60 \%)$ of them believed that it is doctor's responsibility to take care of and report ADRs. In contrast to our findings, many authors reported that majority of pharmacists were in favor of information on drugs causing ADRs and training on $\mathrm{PhV} .{ }^{13,22,24,27}$

Similar to other studies in the past, we found that $66 \%$ of community pharmacists felt that patients will get benefit from ADRs reporting but majority of them never try to find ADRs (96\%) and never reported ADRs (90\%). ${ }^{22,23}$ Contrary to $32.6 \%$ of participants in study by Prakasam et al, $77 \%$ of participants in our study felt that ADRs reporting will spoil their image in general public as well as create differences with prescribers. This could be one of the reasons for not reporting ADRs. ${ }^{23}$

Prakasam A. et al reported that $56.1 \%$ community pharmacists were in favour of online reporting of ADRs followed by surface mail $(17.1 \%){ }^{23}$ In our study community pharmacists (86\%) opined that ADRs reporting forms should be collected by someone from them periodically as they are unable to report themselves because of busy schedule.

In contrast to Prakasam A. et al findings, our results showed that only $9 \%$ of participants were in favour of online reporting of ADRs and this finding is in parallel with findings of M. Suyagh et al. ${ }^{22}$

According to $96 \%$ of the pharmacists in this study, busy schedule was a vital factor for under-reporting of ADRs. For under reporting of ADRs same reason was cited by $26.67 \%$ of the community pharmacists of Malappuram, Kerala, India. ${ }^{13}$

Further legal problems or liabilities were considered as constrains in ADR reporting by many pharmacists. ${ }^{13,22}$ 
Table 3: Practices of pharmacists $(\mathrm{N}=200)$ towards ADRs monitoring and reporting.

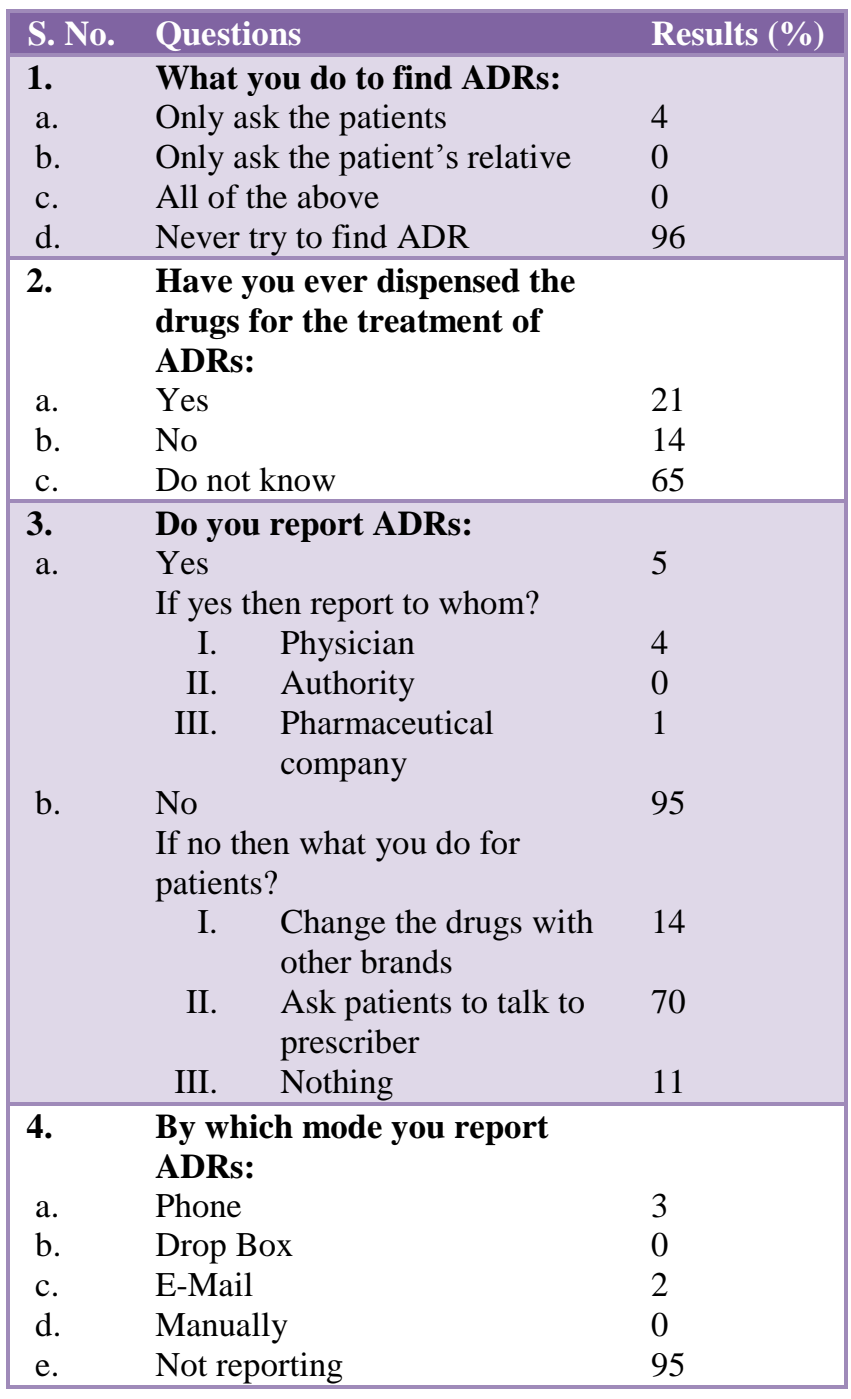

In his study Salim M. et al. found that $45 \%$ of community pharmacists referred the patients who were suffering from ADRs to the physicians. In our study, $70 \%$ of community pharmacists were following the same practice. Further Salim M. et al. added that for the management of ADRs, community pharmacists either asked patients to stop the drug (20\% cases) or gave another medicine to treat ADRs (10\% cases). ${ }^{13}$ In our study we also found that $21 \%$ of community pharmacists dispensed the drugs for treatment of ADRs. Further we observed that $14 \%$ of community pharmacists used to replace the ADRs causing drugs with drugs of different brands but of same chemical compound for the management of ADRs. Although in small percentage, this practice by community pharmacists in our study shows gross lack of knowledge regarding $\mathrm{PhV}$.

\section{CONCLUSION}

In this study community pharmacists had positive attitude towards ADRs reporting but their knowledge and practice regarding $\mathrm{PhV}$ need to be improved. As community pharmacists have opportunity to detect a possible ADR because they are dealing with the counter prescriptions, hence they can help in the management and the reporting of the ADRs.

Awareness and regular training of the community pharmacists in the field of $\mathrm{PhV}$ will be very helpful in providing better patient care. To educate community pharmacists, activities like continuing medical education (CME), training programmes, seminars and conferences should be conducted regularly. Further convenient modes to collect ADRs and tools for periodic monitoring of ADRs reporting should be developed by the regulatory authority to stimulate the community pharmacists to be an essential part of PvPI.

\section{Funding: No funding sources \\ Conflict of interest: None declared \\ Ethical approval: Not required}

\section{REFERENCES}

1. Patel KJ, Kedia MS, Bajpai D, Mehta SS, Krishnasagar NA, Gogtay NJ. Evalution of the prevalence and economic burden of adverse drug reactions presenting to the medical emergency department of tertiary care referral centre: A prospective study. BMC Pharmacol Toxicol. 2007;7(1):83.

2. Rajakannan T, Mallayasamy S, Guddattu V, Kamath A, Vilakkthala R, Rao PG, et al. Cost of adverse drug reactions in a south Indian tertiary care hospital. J Clin Pharmacol. 2012;52(4):559-65.

3. Al Hamid A, Ghaled M, Al jadhey H, Aslanpour Z. A systematic review of hospitalization resulting from medicine-related problems in adult patients. Br J Clin Pharmacol. 2014;78(2):202-17.

4. Khan LM. Comparative epidemiology of hospitalacquired adverse drug reactions in adult and children and their impact on cost and hospital stay-a systematic review. Eur J Clin Pharmacol. 2013;69(12):1985-96.

5. Beijer HJ, DeBlaey CJ. Hospitalizations caused by adverse drug reactions (ADRs): A meta-analysis of observational studies. Pharm World Sci. 2002;24(2):46-54.

6. Sengupta A. Universal Health care in India making it public. Ontario, Canada: IRDC; 2013:23.

7. Kulkarni RD. Reporting systems for rare side effects of non-narcotic analgesics in India. Problems and opportunities. Med Toxicol. 1986;1(1):110-3.

8. Gupta YK. Ensuring Patient Safety - Launching the New Pharmacovigilance Programme of India. Pharmatimes. 2010;42(8):21-6.

9. Edwards I, Olsson S. WHO: global monitoring. In: Mann RD, Andrew E, editors. Pharmacovigilance. Chichester: John Wiley \& Sons; 2002:169-82.

10. Ahmad SR. Adverse drug event monitoring at the Food and Drug Administration. J Gen Intern Med. 2003;18:57-60. 
11. Kalaiselvan V, Prasad T, Singh A. Current Status of Adverse Drug Reactions Monitoring Centres under Pharmacovigilance Programme of India. Indian J Pharm Prac. 2014;7:19-22.

12. Lihite RJ, Lahkar M. An update on the Pharmacovigilance Programme of India. Front. Pharmacol. 2015;6:194.

13. Salim M. The Current Perspective of Community Pharmacists towards Pharmacovigilance. J Pharmacovigil. 2015;3:180.

14. Major E. The yellow card scheme and the role of pharmacists as reporters. Pharm J. 2002;269(7205):25-6.

15. Shulman JI, Shulman S, Haines AP. The prevention of adverse drug reactions--a potential role for pharmacists in the primary care team? J R Coll Gen Pract. 1981;31(228):429-34.

16. Available from: http://timesofindia.indiatimes.com/india/Number-ofdoctors-on-the-rise-but-ratio-to-patients-still-dismal/a rticleshowprint/49082531.cms

17. Rehan HS, Sah RK, Chopra D. Comparison of knowledge, attitude and practices of resident doctors and nurses on adverse drug reaction monitoring and reporting in a tertiary care hospital. Indian $\mathbf{J}$ Pharmacol. 2012;44(6):699-703.

18. Bhagavathula AS, Elnour AA, Jamshed SQ. Health Professionals' Knowledge, Attitudes and Practices about Pharmacovigilance in India: A Systematic Review and Meta-Analysis. 2016 Jan;11(3):e0152221.

19. Murdaugh LB. Competence Assessment Tools for Health-System Pharmacies. $\left(4^{\text {th }}\right.$ ed), American Society of Health System Pharmacists, USA: 2007:439-40.
20. Zolezzi M, Parsotam N. Adverse drug reaction reporting in New Zealand: implications for pharmacists. Ther Clin Risk Manag. 2005;1(3):181-8.

21. Parthasarathy G, Karin NH, Milap N. Clinic Pharmacy Book: Essential Concepts and Skills. Hyderabad: Universities Press; 2008:43-53.

22. Suyagh M, Farah D, Farha RA. Pharmacist's knowledge, practice and attitudes toward pharmacovigilance and adverse drug reactions reporting process. Saudi Pharmaceutical Journal. 2015;23:147-53.

23. Nagaraju K, Satheesh KV, Shankar U, Banu R. Creating Awareness of Adverse Drug Reactions in Community Pharmacists. Indian J Pharm Practice. 2015;8(2):72-7.

24. Prakasam A, Nidamanuri A, Kumar S. Knowledge, perception and practice of pharmacovigilance among community pharmacists in South India. Pharmacy Practice. 2012;10(4):222-6.

25. Bawazir AS. Attitude of community pharmacists in Saudi Arabia towards ADR reporting. Saudi Pharma J. 2006 Jan;1(14):75-83.

26. Tandon VR, Mahajan V, Khajuria V, Gullani Z. Under-reporting of adverse drug reactions: A challenge for pharmacovigilance in India. Indian $\mathbf{J}$ Pharmacol. 2015;47(1):65-71.

27. Kumari S, Senthilkumar P. Comparison of knowledge, attitude and practice towards pharmacovigilance between industrial and hospital pharmacists. Int J Pharm. 2015;5(4):1091-102.

Cite this article as: Sah RK, Chandane RD, Krishna, Manocha S, Kapur A. Knowledge, attitude and practice of pharmacovigilance among community pharmacists in Delhi, India. Int J Basic Clin Pharmacol 2017;6:618-23. 